\title{
Study on underwater hyperbaric dry GMAW welding
}

\author{
De-Yu TANG ${ }^{1}$ a , Hu-Li NIU ${ }^{1}$, Long XUE² ${ }^{2}$ Bo SUN ${ }^{1}$, Tao LV² ${ }^{2}$ Zong-Tao FANG ${ }^{1}$ \\ ${ }^{1}$ Research Institute of Engineering Technology of CNPC, 40 Jintang Road Tanggu Tianjin 300451, \\ P. R. China \\ ${ }^{2}$ Beijing Institute of Petrochemical Technology, Daxing Beijing, 102617, P. R. China \\ atangdy@cnpc.com.cn
}

Keyword: Underwater welding, Hyperbaric dry method, GMAW, Arc characteristic, Droplet transfer

Abstract. Hyperbaric dry welding is an effective way of underwater repair in offshore engineering. Though various welding methods have been attempted at home and abroad for years, problems and limitations exist. This paper conducted a systematic study on character of GMAW method in hyperbaric dry environment. Experimental study on arc characteristics and the establishment of welding process stability are both developed by means of determination of test condition and the application of High-speed camera technology. Combining with analysis of microstructure and mechanical property of welded joints, a complete technology is formed. The research has opened a new road for the development of welding technology in underwater repair engineering.

\section{Introduction}

Ocean development is an important direction of petroleum industry. A enormous increase occur in submerged pipelines along with the offshore oil and gas resources development and utilization. Underwater maintain is becoming more extrusive due to the long-term operation. Research and develop welding and repair technology with practical applicability and adaptive capacity for submarine pipeline is becoming a more and more urgent task. The welding in water environment is totally different from on land. Underwater wet welding is characterized by poor visibility, high hydrogen content, fast cooling rate and poor welding forming, joint quality cannot meet the requirement of pipeline welding. Hyperbaric dry underwater welding whose electric arc burns stability and droplet transfer is in high pressure gas environment show good quality guarantee, which the welding process is achieved by automated and intelligentized welding system and remote control. According to welding condition and quality requirements, arc characteristic, droplet transfer, welding forming and property of welded joint is carried out in this paper, which lays the foundation for the development of offshore oil and has a good application prospect.

\section{The establish of experimental condition and method}

\section{Design of test chamber}

The test chamber, which can simulate underwater dry welding condition, consist of a shell satisfying the requirement of pressure, a hatch door open automatically, a hole for welding equipment and experimental apparatus, a observation port and smoke exhausting device which keep the pressure balance. 

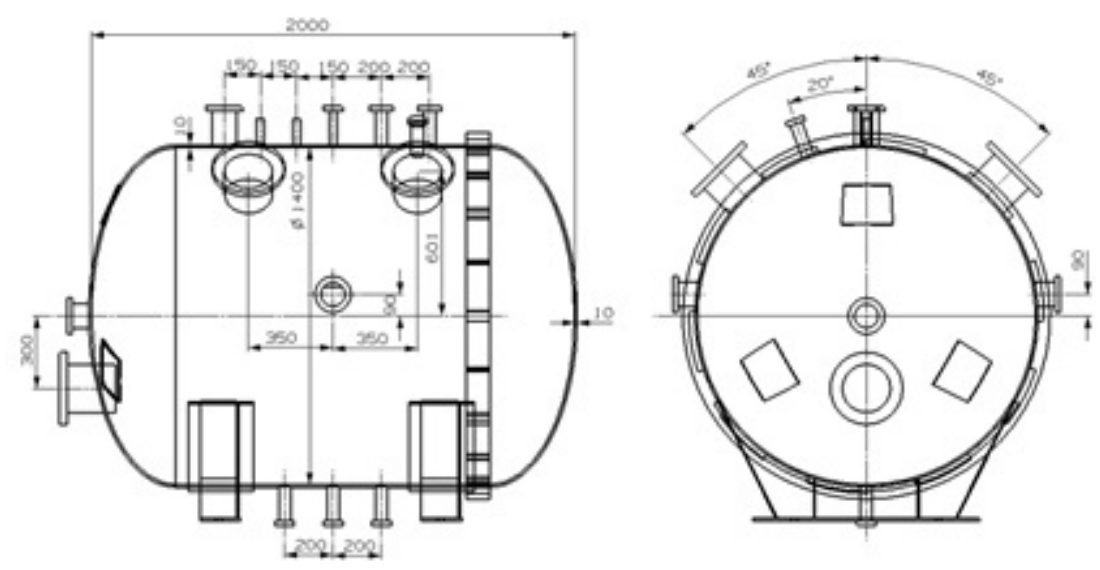

(a) 2d detail map

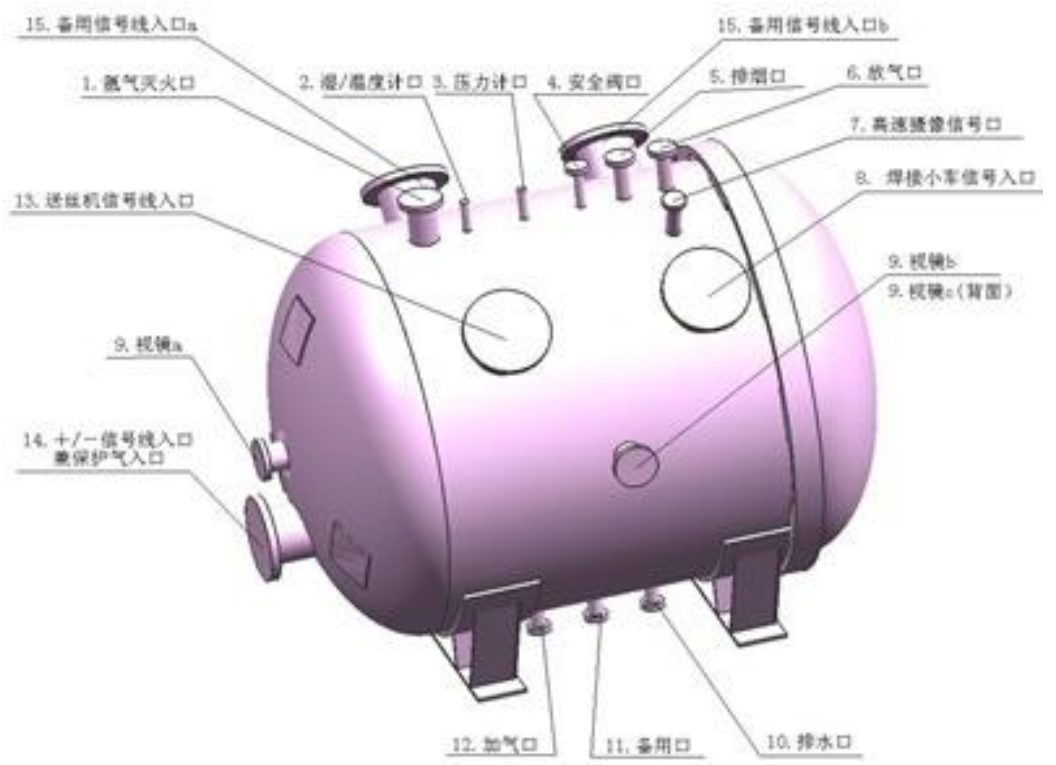

(b) $3 \mathrm{~d}$ drawing

Fig.1 high pressure welding test module

\section{Equipment and apparatus}

Special welding test-bed, air compressor, welding equipment, observation and detecting instrument are used in the experiment. Welding test-bed, wire feed and welding torch are installed in the pressure chamber, welding power source (CMT4000) and control system are placed outside the chamber. All the equipment and apparatus are shown in figure 2 and figure 3. 


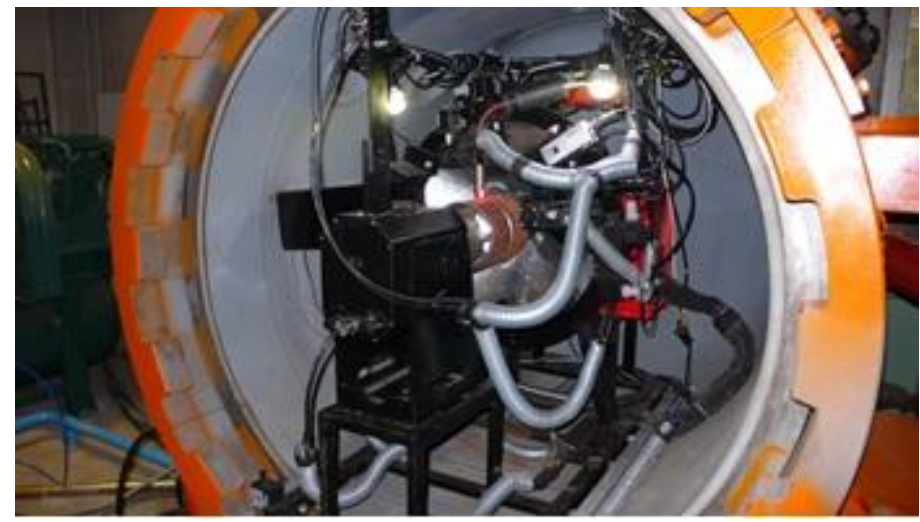

Fig. 2 Layout of equipment in the cabin

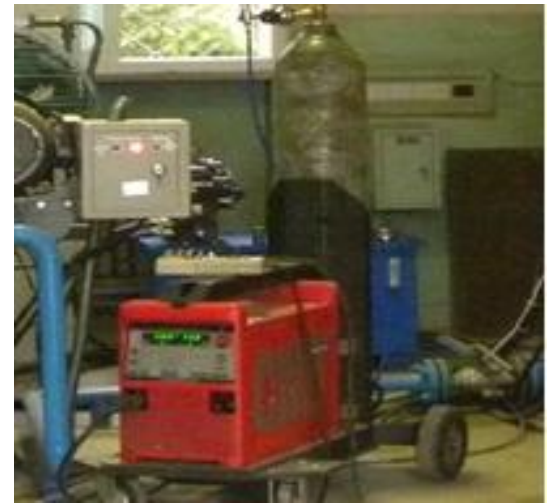

Fig. 3 Welding power

\section{Arc stability test}

\section{Welding blast test in air pressure environment}

In order to remove seawater and obtain dry environment, high pressure gas is charged into the dry cabin in the underwater dry environment. The gas can be air, inert gas or gas mixture including inert gas. Obviously air is the most economically beneficial, however, blasting may occur when arc-time. Blasting test is safe when conducted in shallow water for GTAM. Due to GMAW is different from TIG and need more measuring and observing instruments, blasting tests were conducted first in high-pressure air environment. The results are shown in table 1.

Table 1 shielding gas blasting test in air pressure environment

\begin{tabular}{|c|c|c|c|}
\hline $\begin{array}{c}\text { Air pressure } \\
(\mathrm{MPa})\end{array}$ & $\begin{array}{c}\text { Shielding gas } \\
\text { flow } \\
(\mathrm{L} / \mathrm{min})\end{array}$ & $\begin{array}{c}\text { Welding } \\
\text { current } \\
(\mathrm{A})\end{array}$ & $\begin{array}{c}\text { Arcing and record of } \\
\text { observations }\end{array}$ \\
\hline \multirow{2}{*}{0.2} & 20 & 140 & Arc stable \\
\cline { 2 - 4 } & 20 & 180 & Arc stable \\
\hline \multirow{2}{*}{0.4} & 30 & 140 & Arc stable \\
\cline { 2 - 4 } & 30 & 180 & Arc stable \\
\hline \multirow{2}{*}{0.6} & 50 & 140 & Arc unstable, Splash obvious \\
\cline { 2 - 4 } & 50 & 180 & Arc unstable, Splash obvious \\
\hline
\end{tabular}

It is known by table 1 that in the condition of $0.1 \mathrm{MPa}-0.6 \mathrm{MPa}$ air pressure, shielding gas ( $\mathrm{Ar}$ $82 \%+\mathrm{CO}_{2} 18 \%$ ) and welding current $140 \mathrm{~A}-180 \mathrm{~A}$, there is no phenomena of flame burning or blasting, which not qualified to ignite testing apparatus around, so it is capable of ensure the security of the test.

\section{Arc characteristic of high pressure}

\section{The influence of environmental pressures}

In order to verify the stability of welding arc in high pressure, two welding mode was employed: one is CMT method; the other is convention GMAW with cooperative control.

The base metal is X65 steel pipe with the dimension $\Phi 168 \times 8$, welding sire is JM-56 with diameter $\Phi 1.0 \mathrm{~mm}$, wire extension $10 \mathrm{~mm}$, shielding gas $\mathrm{Ar}+\mathrm{CO} 2$, gas flow $20 \mathrm{~L} / \mathrm{min}$. Test results are as follows:

(1) CMT mode

Arc voltage both present rising trend with the environment pressure increasing and current 
increasing in different current, which is shown in figure 4 (a). The welding arc is stable curing welding process.

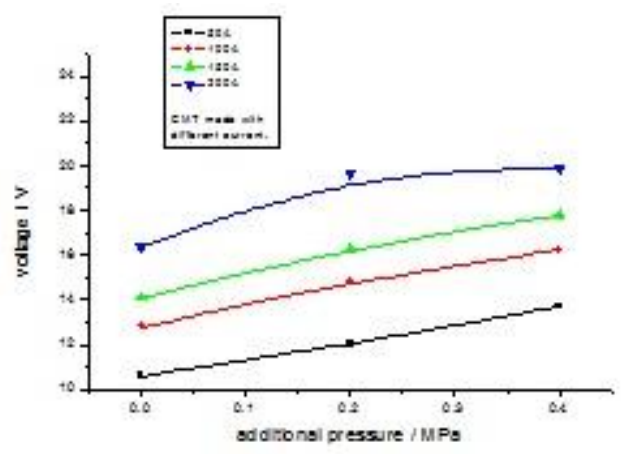

(a) CMT

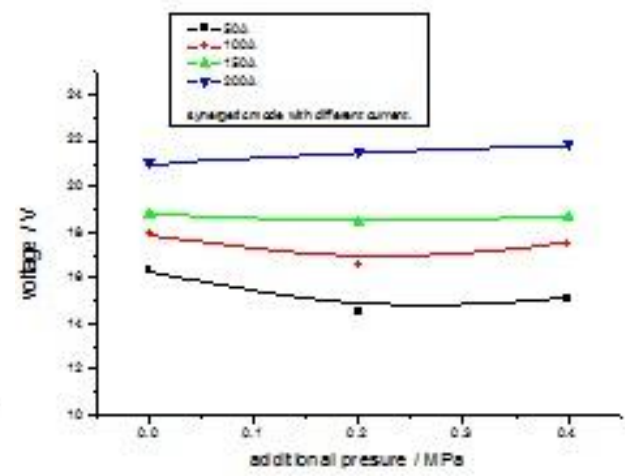

(b) Unitary synergy MAG

Fig. 4 The relation between environment pressure and arc voltage

(2) Unitary synergy MAG

It is known from figure 4 that arc voltage increase with the increasing of current. Arc voltage increase with the increase of environment pressure as well, but the law is not obvious. It is possible concerned with great fluctuation of arc voltage. The welding arc is basically stable curing welding process. There is more weld spatter in cooperative control compared to CMT mode.

Arc voltage increases with the increase of environment pressure. To obtain stable welding process, output voltage should be enhanced with the increase of current, or welding source with dropping characteristic can be employed.

\section{The influence of weld current}

Arc voltage both present increasing trend with the current increasing in either CMT or MAG mode, which is shown in figure 5. That is arc have the rising characteristic. The welding arc is stable curing welding process.

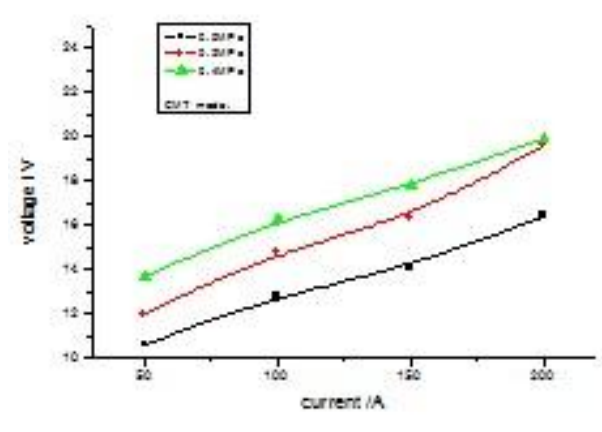

(a) CMT

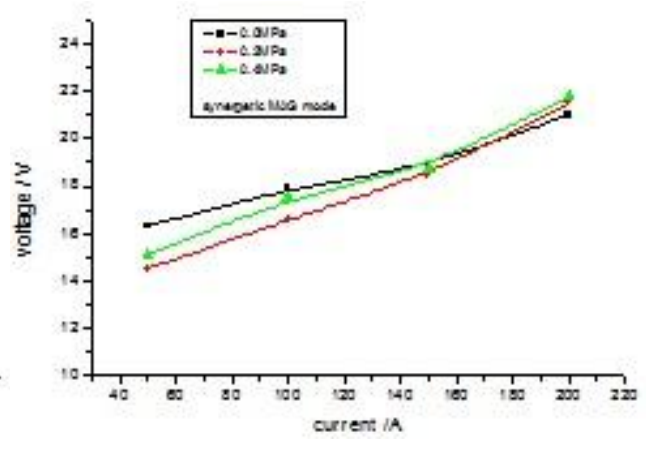

(b) Unitary synergy MAG

Fig. 5 The relation between weld current and arc voltage when environmental pressure change

\section{Arc feature of high environment}

The welding process was record high speed camera system whose speed is 1000f/s. Arc feature corresponding to different welding mode, different shielding gas, different environment pressure and different current. Maximum diameter and height of arc was compared to find some laws by image processing.

Arc morphology photos are shown in figure 6 in different environment pressure. Arc height increases appreciably along with the increase of environment pressure. Generally, arc increases with 
the increase of environment pressure. Because when environment pressure has been increased, arc voltage increases correspondingly in the case of the same current (see research on arc static characteristic ahead). Then the arc energy increases, arc bright area is greater.

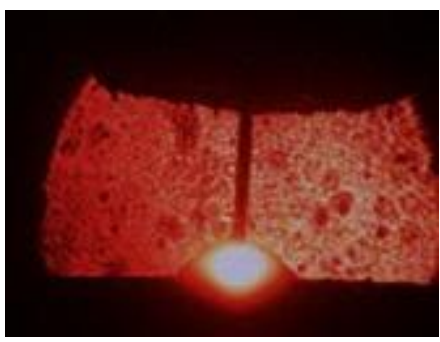

(a) $0.1 \mathrm{MPa}, 200 \mathrm{~A}$

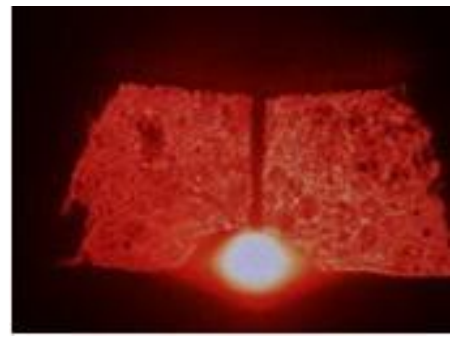

(b) $0.3 \mathrm{MPa}, 200 \mathrm{~A}$

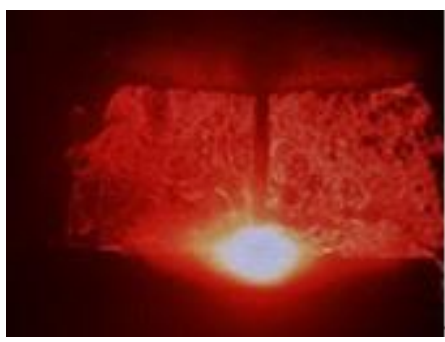

(c) $0.5 \mathrm{MPa}, 200 \mathrm{~A}$

Fig. 6 Arc photos of different pressure (CMT, shielding gas Ar+CO2)

\section{Structure and property of welded joints}

CMT mode was employed in the welding. The pipe rotated driven by the workbench, and welding gun was foxed on particular position which including downward welding, vertical down welding, over-head position welding. The specimen is X65 pipeline with dimension of $\Phi 168 \mathrm{~mm} \times 12 \mathrm{~mm}$, welding Materials JM-68, GB\ER55-G, shielding gas Ar80\% $+\mathrm{CO}_{2} 20 \%$, environment pressure 0 $\mathrm{MPa}$ (ordinary pressure) and $0.4 \mathrm{MPa}$ respectively. Test parameters are shown in table 2.

Table 2 Welding test parameters

\begin{tabular}{|c|c|c|c|c|c|c|c|}
\hline Welding position & $\begin{array}{c}\text { Environment } \\
\text { pressure }\end{array}$ & Layers & $\begin{array}{c}\text { Curre } \\
\mathrm{nt}\end{array}$ & $\begin{array}{c}\text { Voltag } \\
\text { e }\end{array}$ & $\begin{array}{l}\text { Swing } \\
\text { speed }\end{array}$ & Amplitude & $\begin{array}{l}\text { Shielding } \\
\text { gas flow } \\
(\mathrm{L} / \mathrm{min})\end{array}$ \\
\hline \multirow{4}{*}{ downward welding } & \multirow{2}{*}{$0.4 \mathrm{Mpa}$} & Root & 130 & 17.0 & 170 & 60 & 30 \\
\hline & & Filling、 Cap & 150 & 17.5 & $180 \sim 250$ & $105 \sim 210$ & 30 \\
\hline & \multirow{2}{*}{$0.0 \mathrm{Mpa}$} & Root & 130 & 16.0 & 185 & 60 & 20 \\
\hline & & Filling、Cap & 150 & 16.5 & $200 \sim 250$ & $100 \sim 200$ & 20 \\
\hline \multirow{4}{*}{$\begin{array}{l}\text { vertical down } \\
\text { welding }\end{array}$} & \multirow{2}{*}{$0.4 \mathrm{Mpa}$} & Root & 150 & 17.5 & 200 & 70 & 30 \\
\hline & & Filling、Cap & 165 & 17.5 & $200 \sim 250$ & $130 \sim 230$ & 30 \\
\hline & \multirow{2}{*}{$0.0 \mathrm{Mpa}$} & Root & 150 & 16.5 & 210 & 70 & 20 \\
\hline & & Filling、 Cap & 140 & 16.5 & $200 \sim 250$ & $80 \sim 220$ & 20 \\
\hline \multirow{4}{*}{$\begin{array}{l}\text { over-head position } \\
\text { welding }\end{array}$} & \multirow{2}{*}{$0.4 \mathrm{Mpa}$} & Root & 170 & 18.0 & 170 & 71 & 30 \\
\hline & & Filling、Cap & 170 & 18.0 & $175 \sim 250$ & $115 \sim 230$ & 30 \\
\hline & \multirow{2}{*}{$0.0 \mathrm{Mpa}$} & Root & 160 & 16.5 & 160 & 40 & 20 \\
\hline & & Filling、Cap & 145 & 16.3 & $195 \sim 250$ & $83 \sim 210$ & 20 \\
\hline
\end{tabular}

\section{Metallographic analysis of welded joints}

(1) Ordinary pressure

Typical metallographic structure of welded joint at ordinary pressure is shown from figure 7 to figure 10 . 


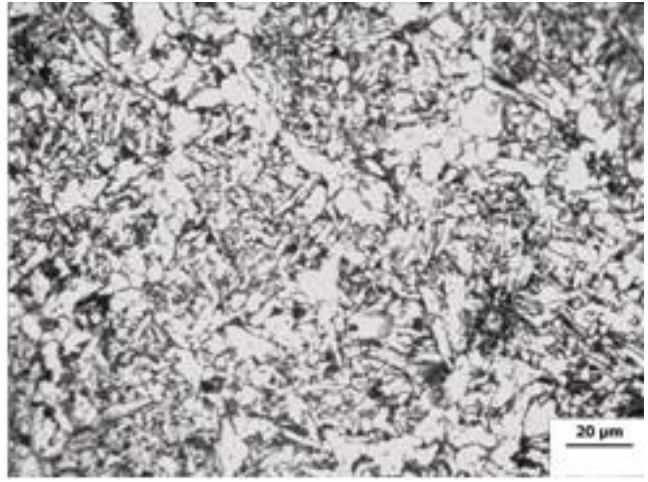

Fig. 7 HAZ

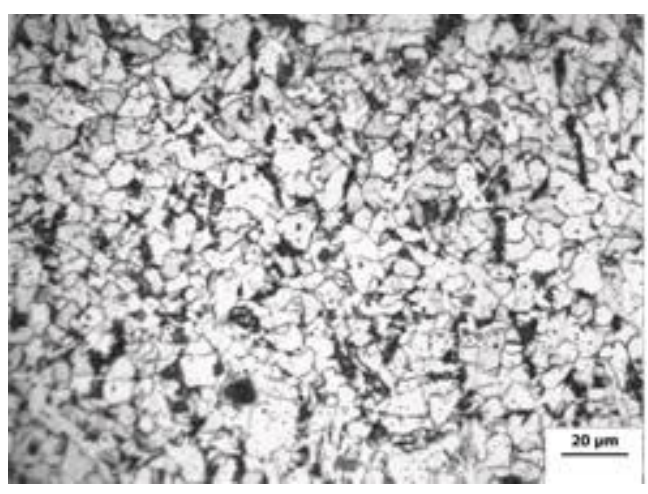

Fig. 9 Centre weld

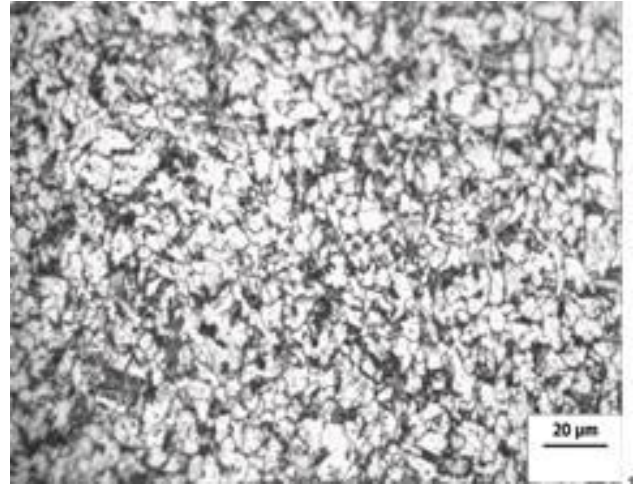

Fig. 8 Root of weld

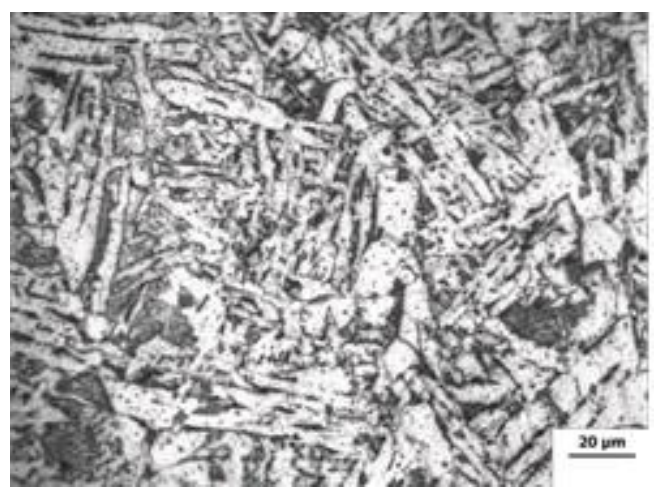

Fig. 10 Cap weld

It can be seen from figure 7 to figure 10 that there is a great number of upper bainite in centre weld and cap weld at $0.4 \mathrm{MPa}$, which present featheriness. The forming of upper bainite has to process $\mathrm{C}$ redistribution and $\mathrm{Fe}$ crystal lattice reorganize. $\mathrm{C}$ diffuses and redistributes in austenite with a certain speed. While Fe and alloy atoms almost don't spread. During the transformation of $\gamma \rightarrow \alpha$, meanwhile $\mathrm{C}$ comes off ferrite, which across phase boundaries of ferrite and spread to austenite, then forming upper bainite. Because of welding was at $0.4 \mathrm{MPa}$, diffusion velocity of $\mathrm{C}$ atoms was affected, thus mass upper bainite appear in centre weld and cap weld. The exist of upper bainite is bound to low the toughness of welded joints. In addition, carbide is more dispersed, this is also the result of the change of diffusion velocity of $\mathrm{C}$ atoms at high pressure.

mechanics performance analysis of welded joints

According to AWS D3.6, the specimen was machined after NDT, then mechanics performance was carried out. The results are shown in table 3, table 4 and figure 11 .

Table 3 Transverse tension test data

\begin{tabular}{|c|c|c|c|c|}
\hline \multicolumn{2}{|c|}{$\begin{array}{c}\text { Sample } \\
\text { Numbers }\end{array}$} & $\begin{array}{c}\text { Tensile strength } \\
(\mathrm{MPa})\end{array}$ & $\begin{array}{c}\text { Percentage } \\
\text { elongation } \\
(\%)\end{array}$ & Rupture position \\
\hline \multirow{2}{*}{$0 \mathrm{MPa}$} & $\mathrm{T} 1$ & 565 & 14 & Weld \\
\cline { 2 - 5 } & $\mathrm{T} 2$ & 560 & 12 & Weld \\
\hline 0.4 & $\mathrm{~T} 1$ & 535 & 11 & Weld \\
\cline { 2 - 5 } $\mathrm{MPa}$ & $\mathrm{T} 2$ & 570 & 14 & Weld \\
\hline
\end{tabular}


Table 4 Charpy impact test data at low temperature

\begin{tabular}{|c|c|c|c|c|c|}
\hline \multirow{2}{*}{$\begin{array}{c}\text { Sample } \\
\text { name }\end{array}$} & $\begin{array}{c}\text { Location of } \\
\text { notch }\end{array}$ & $\begin{array}{c}\text { Impact energy } \\
(\mathrm{J})\end{array}$ & $\begin{array}{c}\text { Minimum } \\
\text { impact } \\
\text { energy } \\
(\mathrm{J})\end{array}$ & $\begin{array}{c}\text { Average } \\
\text { impact } \\
\text { energy }(\mathrm{J})\end{array}$ & $\begin{array}{c}\text { Temperature } \\
\left({ }^{\circ} \mathrm{C}\right)\end{array}$ \\
\hline \multirow{2}{*}{$0.0 \mathrm{MPa}$} & Weld & $144,133,137$ & 133 & 138 & \multirow{2}{*}{-20} \\
\cline { 2 - 6 } $0.4 \mathrm{MPa}$ & HAZ & $107,127,84$ & 84 & 106 & \\
\cline { 2 - 6 } & Weld & $47,57 、 78$ & 47 & 61 & \\
\hline
\end{tabular}

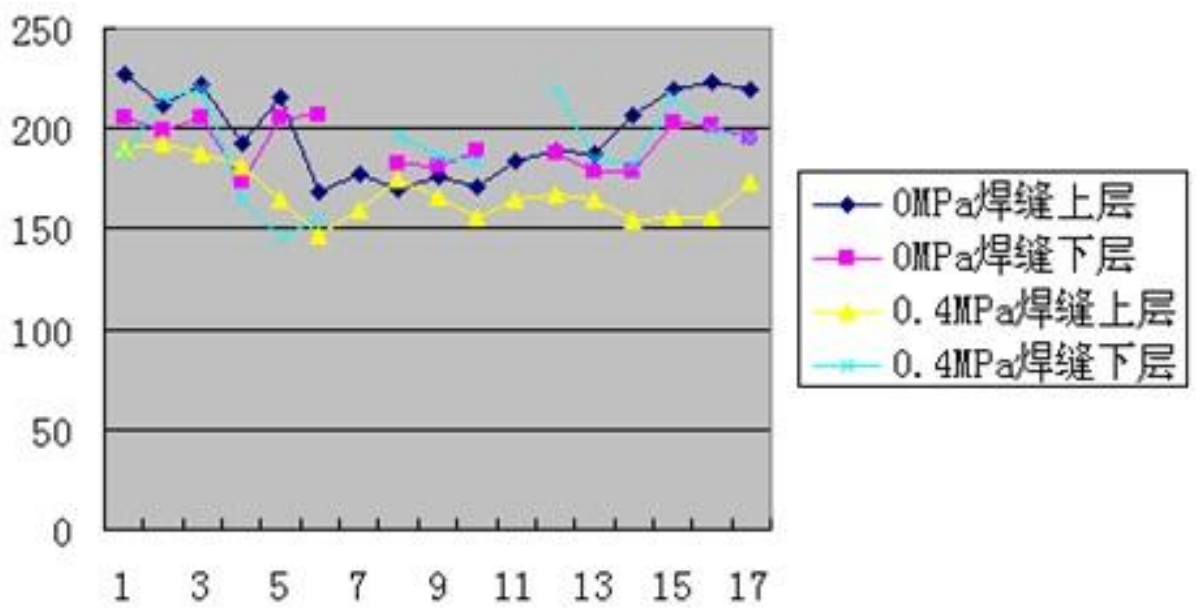

Fig. 11 HV10 hardness test data of welded joints

Imperfections were not found in macro metallographic examination by magnifier macroscopic; guided bend test was qualified as well. The test results demonstrate that all the index sign meet the requirements of the standard. Qualified welding joints are able to obtained according to this specification in underwater high pressure dry GMAW welding.

\section{Conclusions}

(1) Blasting test at air pressure demonstrate that there is no phenomena of flame burning or exploding in the pressure chamber by remodeling of hyperbaric chamber and effective protection to special parts.

(2) In order to obtain stable welding process, the increase of output voltage of power source is necessary. With respect to wire extension, lower limit at ordinary pressure is advisable, shielding gas flow should be more than $15 \mathrm{~L} / \mathrm{min}$. Compared to unitary mode, CMT is the first choice for high pressure welding method at different environment pressure, which welding process is relatively stable.

(3) According to AWS D3.6, welding processes and techniques were carried out, and the results meet the requirements of standard through mechanics test.

(4) The research result of this paper opens up a new way to underwater welding in pipeline repairing. With the development of offshore oil engineering and related technology, the technology 
is sure to have a good application prospect.

\section{Reference}

[1] LP Jiang, ZH Wang, XD Jiao, i.e. The GTAW Arc Characteristic of Underwater Welding in High Pressure Air Condition [J] Welding Journal, 2007, 28(6):1-4.

[2] YW Shi, XP Zhang, YP Lei, i.e. The Welding Technology in Serve Condition [M] Beijing: Mechanical Publisher, 1999:1-120.

[3] AWS D3.6M: Specification for Underwater Welding[S] 1999. 